\title{
Overview of distinct 5-methylcytosine profiles of messenger RNA in human hepatocellular carcinoma and paired adjacent non-tumor tissues
}

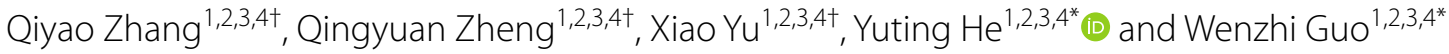

\begin{abstract}
Background: Post-transcriptional methylation modifications, including 5-methylcytosine (m5C) modification, are closely related to the tumorigenesis of cancers. However, the mRNA profile of m5C modification in hepatocellular carcinoma (HCC) is unknown.

Methods: Methylated RNA immunoprecipitation sequencing was performed to identify m5C peaks on mRNA of human HCC tissues and adjacent tissues, and differences in $\mathrm{m} 5 \mathrm{C}$ between the two groups were analyzed. In addition, we conducted a bioinformatics analysis to predict the function of specific methylated transcripts.

Results: We found that there was a noticeable difference in $\mathrm{m} 5 \mathrm{C}$ between $\mathrm{HCC}$ and paired non-tumor tissues, suggesting that $\mathrm{m} 5 \mathrm{C}$ could play a role in the pathogenesis of HCC. In addition, analyses of gene ontology and the Kyoto Encyclopedia of Genes and Genomes showed that the unique distribution pattern of mRNA m5C in HCC was associated with a wide range of cellular functions.
\end{abstract}

Conclusions: Our results revealed different distribution patterns of $\mathrm{m} 5 \mathrm{C}$ in HCC and adjacent tissues and provided new insights into a novel function of m5C RNA methylation of mRNA in HCC progression.

Keywords: mRNA, 5-methylcytosine, Hepatocellular carcinoma, RNA methylation, MeRIP-seq

\section{Background}

Hepatocellular carcinoma $(\mathrm{HCC})$ is one of the most widespread cancers, and it has an extremely poor prognosis, contributing to nearly 662,000 deaths per annum $[1,2]$. The incidence rate of HCC is ranked sixth-highest of the cancerous tumors globally, and the number of deaths caused by HCC is ranked third-highest of the tumor-related deaths [3]. Despite marked progress in

\footnotetext{
*Correspondence: fccheyt1@zzu.edu.cn; fccguowz@zzu.edu.cn

${ }^{\dagger}$ Qiyao Zhang, Qingyuan Zheng and Xiao Yu contributed equally to this work

${ }^{1}$ Department of Hepatobiliary and Pancreatic Surgery, The First Affiliated Hospital of Zhengzhou University, No.1 Jianshe Road, Zhengzhou 450052, Henan, China

Full list of author information is available at the end of the article
}

treatment, due to its late diagnosis, high metastasis, and high recurrence rate, the lethal rate of hepatocellular carcinoma remains high [4-7]. In addition to the widely used alpha-fetoprotein (AFP), protein induced by vitamin $\mathrm{K}$ absence or antagonist-II (PIVKA-II), and third electrophoretic form of lentil lectin-reactive AFP (AFPL3) tumor markers for HCC, some miRNAs and new biomarkers, such as heat shock protein $90-\alpha(\mathrm{Hsp} 90 \alpha)$ and a metabolite biomarker, have been discovered recently, and have shown high performance in the diagnosis of HCC [8-11]. Nevertheless, the early diagnosis of hepatocellular carcinoma still requires further investigation. Personalized immunotherapy based on immunophenotyping has become a research hotspot in recent years $[6,12]$, but the stability and effectiveness of this model is

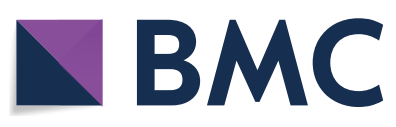

(c) The Author(s) 2020. This article is licensed under a Creative Commons Attribution 4.0 International License, which permits use, sharing, adaptation, distribution and reproduction in any medium or format, as long as you give appropriate credit to the original author(s) and the source, provide a link to the Creative Commons licence, and indicate if changes were made. The images or other third party material in this article are included in the article's Creative Commons licence, unless indicated otherwise in a credit line to the material. If material is not included in the article's Creative Commons licence and your intended use is not permitted by statutory regulation or exceeds the permitted use, you will need to obtain permission directly from the copyright holder. To view a copy of this licence, visit http://creativeco mmons.org/licenses/by/4.0/. The Creative Commons Public Domain Dedication waiver (http://creativecommons.org/publicdomain/ zero/1.0/) applies to the data made available in this article, unless otherwise stated in a credit line to the data. 
still uncertain. Therefore, a deeper understanding of the pathogenesis of HCC and the identification of new biomarkers are essential for early diagnosis and developing new therapeutic targets of HCC.

Epigenetic dysregulation plays a critical role in the initiation and progression of cancer, and post-transcriptional modifications, such as RNA methylation, have attracted the attention of many researchers [13]. With advances in high-throughput technologies, such as m5C-RNA immunoprecipitation (IP), researchers have been able to characterize RNA methylation sites in-depth [14]. Increasing evidence has shown that N6-methyladenosine (m6A), which is the most prevalent internal mRNA modification, is related to mRNA metabolism, such as regulating mRNA stability and splicing [15-19]. In addition, related studies have shown the potential molecular mechanism in cancer, including HCC. Li et al. found that inhibiting the generation of YTHDTF2, which is an m6A reader protein, blocked anti-miR-145-enhanced proliferation, suggesting that miR-145 suppresses the proliferation of HCC cells by regulating m6A reading [20, 21]. 5-methylcytosine $(\mathrm{m} 5 \mathrm{C})$, which is another post-transcriptional RNA modification, has been identified in stable and highly abundant tRNAs, rRNAs, and mRNAs [22-24]. In addition, NSUN2 has been identified as a methyltransferase, while ALYREF and YBX1 have been identified as an $\mathrm{m} 5 \mathrm{C}$ reader [25]. Studies have shown that $\mathrm{m} 5 \mathrm{C}$ modification is necessary for the stable and efficient translation of tRNA and plays an important role in rRNA processing, structuring, and translation [26-29]. This modification has conservative, tissue-specific, and dynamic characteristics in mammalian transcriptomes [25]. Thus, a study on mice demonstrated that $\mathrm{m} 5 \mathrm{C}$ is primarily enriched near the translation initiation codon of the embryonic stem cells and brain of mice [20]. However, this feature has not been found in Arabidopsis [30], and the distribution characteristics of $\mathrm{m} 5 \mathrm{C}$ could be different for different cell types. Chen et al. [31] demonstrated that m5C can promote the pathogenesis of bladder cancer by stabilizing mRNAs. However, the quantity, distribution, and functions of $\mathrm{m} 5 \mathrm{C}$ in $\mathrm{HCC}$ are still unclear.
We performed a m5C-specific analysis and in-depth bioinformatics analysis of $\mathrm{m} 5 \mathrm{C}$ in mRNA in human $\mathrm{HCC}$ and paired adjacent non-tumor tissues. The results showed marked differences in the amount and distribution of $\mathrm{m} 5 \mathrm{C}$ between HCC and adjacent tissues: the number of $\mathrm{m} 5 \mathrm{C}$ methylation peaks in $\mathrm{HCC}$ was much more than that in paired adjacent non-tumor tissues, and the difference in distribution was wide and involved all chromosomes. Bioinformatics analysis showed that the two groups, with different methylation, could cause different changes in cell function. Our findings suggest a possible association between $\mathrm{HCC}$ and $\mathrm{m} 5 \mathrm{C}$ in mRNA and predict possible functional changes caused by this difference in $\mathrm{m} 5 \mathrm{C}$.

\section{Materials and methods}

\section{RNA extraction and fragmentation}

Each pair of HCC tissues and paired adjacent non-tumor tissues were obtained from the First Affiliated Hospital of Zhengzhou University. We collected six groups of biological replicates (Table 1). Subsequently, we extracted total RNA using TRIzol reagent (Invitrogen Corporation, CA, USA) following the manufacturer's instructions. A Ribo-Zero rRNA Removal Kit (Illumina, Inc., CA, USA) was used to reduce the rRNA content. The quality of RNA was evaluated using its OD260/OD280 ratio, which is a measure of the nucleotide to protein ratio based on optical density measured using spectrophotometry. The purity of RNA with an OD260/OD280 value range of 1.8-2.1 was considered acceptable, and the RNA extracted from all samples met this standard.

\section{Library construction and sequencing}

Methylated RNA immunoprecipitation sequencing (MeRIP-seq) was performed based on a previously reported procedure [32]. Total RNA was lysed into 100 base pair fragments using a GenSeqTM m5C RNA IP Kit (GenSeq Inc, China), and $\mathrm{m} 5 \mathrm{C}$ immunoprecipitation was performed followed by RNA-seq library generation using a NEBNext ${ }^{\circledR}$ Ultra II Directional RNA Library Prep Kit (New England Biolabs, Inc, USA).

Table 1 Clinical characteristics of HCC patients

\begin{tabular}{|c|c|c|c|c|c|c|c|}
\hline Age & Gender & $\operatorname{AFP}(n g / m g)$ & Stage (BCLC) & Tumor size $(\mathrm{cm})$ & Tumor metastasis & HBsAG & $\mathrm{HBcAb}$ \\
\hline 47 & Male & 2.19 & A1 & $7 * 5.5 * 4$ & Right lobe of liver & - & + \\
\hline 45 & Male & 614.1 & A1 & $3.8 * 3.3 * 2.7$ & No & + & + \\
\hline 60 & Male & 4602 & $A 2$ & $6 * 5.3 * 3.5$ & No & + & + \\
\hline 49 & Male & 191.7 & A1 & $3.5^{*} 2.5^{*} 2$ & No & + & + \\
\hline 78 & Male & 2.83 & A3 & $4.5^{*} 4 * 2$ & No & + & + \\
\hline 45 & Male & 1.69 & $A 2$ & $2.5^{*} 2 * 2$ & No & + & + \\
\hline
\end{tabular}


A BioAnalyzer 2100 system (Agilent Technologies, Inc, USA) was used to evaluate the cDNA library, and library sequencing was performed using an Illumina Hiseq instrument with 150 bp paired-end reads.

\section{Identification and analysis of 5-methylcytosine peaks}

Quality control of the paired-end reads was performed using a quality standard of the probability of an incorrect base call at 1 in 1000 (Q30) in Illumina HiSeq 4000 Sequencer: a Q30>80\% indicated good sequencing quality (Table 2). After conducting quality control, the $3^{\prime}$ adaptors were trimmed and low-quality reads were removed using Cutadapt software (v1.9.3), and highquality clean reads were harvested. Clean reads of input libraries were aligned to a reference genome (GRCh38. gencode. v32) using STAR software [33] and mRNA peaks were identified using DCC software [34]. Next, clean reads of all libraries were aligned to the reference genome using Hisat2 software (v2.0.4) [35]. Then, the $\mathrm{m} 5 \mathrm{C}$ peaks on the mRNA were identified using MACS software [36]. In addition, differentially methylated peaks were identified using DiffReps software [37]: m5C peaks with a fold change $>2$ or $<0.5(P$ value $\leq 0.00001)$ in HCC were considered to be up-regulated methylation or down-regulated methylation. Peaks identified using both software and the section of $\mathrm{m} 5 \mathrm{C}$ that overlapped with the exon of the protein-coding genes were selected using scripts developed in-house for further annotation.

\section{Table 2 The Q30 of simples}

\begin{tabular}{|c|c|c|c|c|}
\hline Patient ID & Sample & Q30 & Sample & Q30 \\
\hline 1 & $\mathrm{HCCIP}$ & $92.39 \%$ & HCC input & $92.91 \%$ \\
\hline 2 & $\mathrm{HCCIP}$ & $92.86 \%$ & HCC input & $94.25 \%$ \\
\hline 3 & $\mathrm{HCCIP}$ & $93.04 \%$ & HCC input & $94.49 \%$ \\
\hline 4 & $\mathrm{HCCIP}$ & $93.28 \%$ & HCC input & $94.03 \%$ \\
\hline 5 & $\mathrm{HCCIP}$ & $93.26 \%$ & HCC input & $91.90 \%$ \\
\hline 6 & HCC IP & $92.17 \%$ & HCC input & $94.04 \%$ \\
\hline 1 & Paired non-tumor IP & $91.86 \%$ & $\begin{array}{l}\text { Paired non-tumor } \\
\text { input }\end{array}$ & $93.04 \%$ \\
\hline 2 & Paired non-tumor IP & $91.77 \%$ & $\begin{array}{l}\text { Paired non-tumor } \\
\text { input }\end{array}$ & $92.96 \%$ \\
\hline 3 & Paired non-tumor IP & $91.55 \%$ & $\begin{array}{l}\text { Paired non-tumor } \\
\text { input }\end{array}$ & $93.81 \%$ \\
\hline 4 & Paired non-tumor IP & $90.36 \%$ & $\begin{array}{l}\text { Paired non-tumor } \\
\text { input }\end{array}$ & $94.10 \%$ \\
\hline 5 & Paired non-tumor IP & $91.16 \%$ & $\begin{array}{l}\text { Paired non-tumor } \\
\text { input }\end{array}$ & $89.47 \%$ \\
\hline 6 & Paired non-tumor IP & $90.86 \%$ & $\begin{array}{l}\text { paired non-tumor } \\
\text { input }\end{array}$ & $92.47 \%$ \\
\hline
\end{tabular}

\section{Statistical analysis}

The $\mathrm{m} 5 \mathrm{C}$ peaks on the mRNA of the six samples in the HCC group were combined to obtain the m5C peaks of the HCC group, and the adjacent tissue group was treated in the same way. Bedtools software was used to find common peaks between the two groups. The sequence of methylated peaks, which was $50 \mathrm{bp}$ on each side of the apex, was scanned using Dreme software [38] to find meaningful motif. The E-values for the motifs were calculated as the enrichment P-value times the number of candidate motifs tested, and the enrichment P-value was calculated using Fisher's Exact Test for the enrichment of the motif in the positive sequences. The lower the E-value of the motif, the higher its credibility. Subsequently, the methylation fold enrichment (FE) of each mRNA of the six pairs of samples was acquired and subjected to $\log 2$ conversion. The logFE value was used for clustering in the heatmap. 2 software package. In addition, we counted the mRNA region where the $\mathrm{m} 5 \mathrm{C}$ peak was located in each sample according to published methods [39] and plotted the results as a pie chart.

\section{Transcriptome sequencing analysis}

High-quality reads were mapped onto the genome (human gencode v32) using hisat2 software (v2.0.4) [35]. Then, HTSeq software (v0.9.1) was used to obtain genelevel raw counts as mRNA expression profiles [40]. Edge $\mathrm{R}$ software (v3.16.5) was used to normalize the data and calculate the fold change and P-value between the two groups of samples to screen for differentially expressed mRNA [41]. Subsequently, the expression levels of these mRNAs were normalized to obtain $\operatorname{logCPM}$ and the average values for the two groups were calculated. A scatterplot of differential expression of methylated genes was draw combining the methylation degree of these genes.

\section{Bioinformatics analysis}

The Gene Ontology (GO) project, which is a structured, controlled vocabulary developed for annotating genes and gene products [42], contains three parts: biological processes (BP), molecular functions (MF), and cellular components $(\mathrm{CC})$. Differentially methylated genes were used to perform GO functional analysis (http://www. geneontology.org) to annotate and speculate on the function of these differentially methylated genes. Gene terms with a $P$-value $<0.05$ were considered statistically significant. Meanwhile, pathway analysis using the Kyoto Encyclopedia of Genes and Genomes (KEGG) (https://david .ncifcrf.gov/)was conducted with differentially methylated genes to annotate and speculate pathways in which they could be involved. The pathways with $P$-values $<0.05$ were considered significantly enriched. In addition, we 
used the enrichment intensity fold change value of the two groups of samples in the MeRIP-seq experiment to rank all the coded genes with signals, and we used the PreRanked mode of gene set enrichment analysis (GSEA) to determine the over-representation and under-representation of all genes in a gene set to observe the differences in the gene sets between the two groups. We selected FDR $<0.25$ as the screening criterion. We also analyzed other GSEA pathways, with a primary focus on TGF-beta signaling, hedgehog signaling pathway, axon guidance, regulation of actin cytoskeleton, and the arrhythmogenic right ventricular cardiomyopathy arc. All processes are described in Fig. 1.

\section{Results}

\section{General features of 5-methylcytosine methylation in human HCC and adjacent tissues}

In general, we found 18,324 clean methylation peaks in HCC tissues and 12,406 clean methylation peaks in adjacent tissues. We mapped up to 10,200 annotated genes of HCC tissues and 7689 annotated genes of adjacent tissues. Of 18,324 methylation peaks, only 7671 appeared in $\mathrm{HCC}$, while only 1753 of 12,406 methylation peaks appeared in adjacent tissues. (Figure 2a, b). There were noticeable differences in the number of $\mathrm{m} 5 \mathrm{C}$ peaks and differentially methylated $\mathrm{m} 5 \mathrm{C}$ peaks. Moreover, for the methylation peaks that only appeared in HCC or adjacent tissues, the number of up-methylated peaks per gene in HCC tissues (2.48 peaks/gene) was smaller than that in adjacent tissues (3.00 peaks/gene), and both of them were markedly higher than the methylated peaks that were present in both samples (1.50 peaks/gene).

When the distribution of mRNA m5C peaks on the chromosomes was analyzed using circos software, it was found that the number and distribution of $\mathrm{m} 5 \mathrm{C}$ peaks on each chromosome were different between HCC and adjacent tissues, with the difference on chromosome one being the most obvious (Fig. 2c). In addition, compared with the sex chromosomes, the autosomes in both groups were more methylated.

\section{Cluster analysis}

The results of the methylation heatmap and cluster analyses showed that clustering of methylation differences could clearly distinguish the HCC group from the adjacent tissues group: there were relative consistencies within the groups and marked differences between the groups (Fig. 2d). Overall, the degree of methylation in the HCC tissues was higher than in the adjacent tissues. In total, 3126 methylation peaks in HCC were identified as up-regulated methylation, and 1103 methylation peaks were detected as down-regulated methylation (Tables 3 and 4).

\section{Motif analysis}

Among the motifs measured in the HCC tissues, CUWCM $(\mathrm{M}=\mathrm{C} / \mathrm{A})$ was the most common and reliable: it was the most likely conserved methylation site motif,

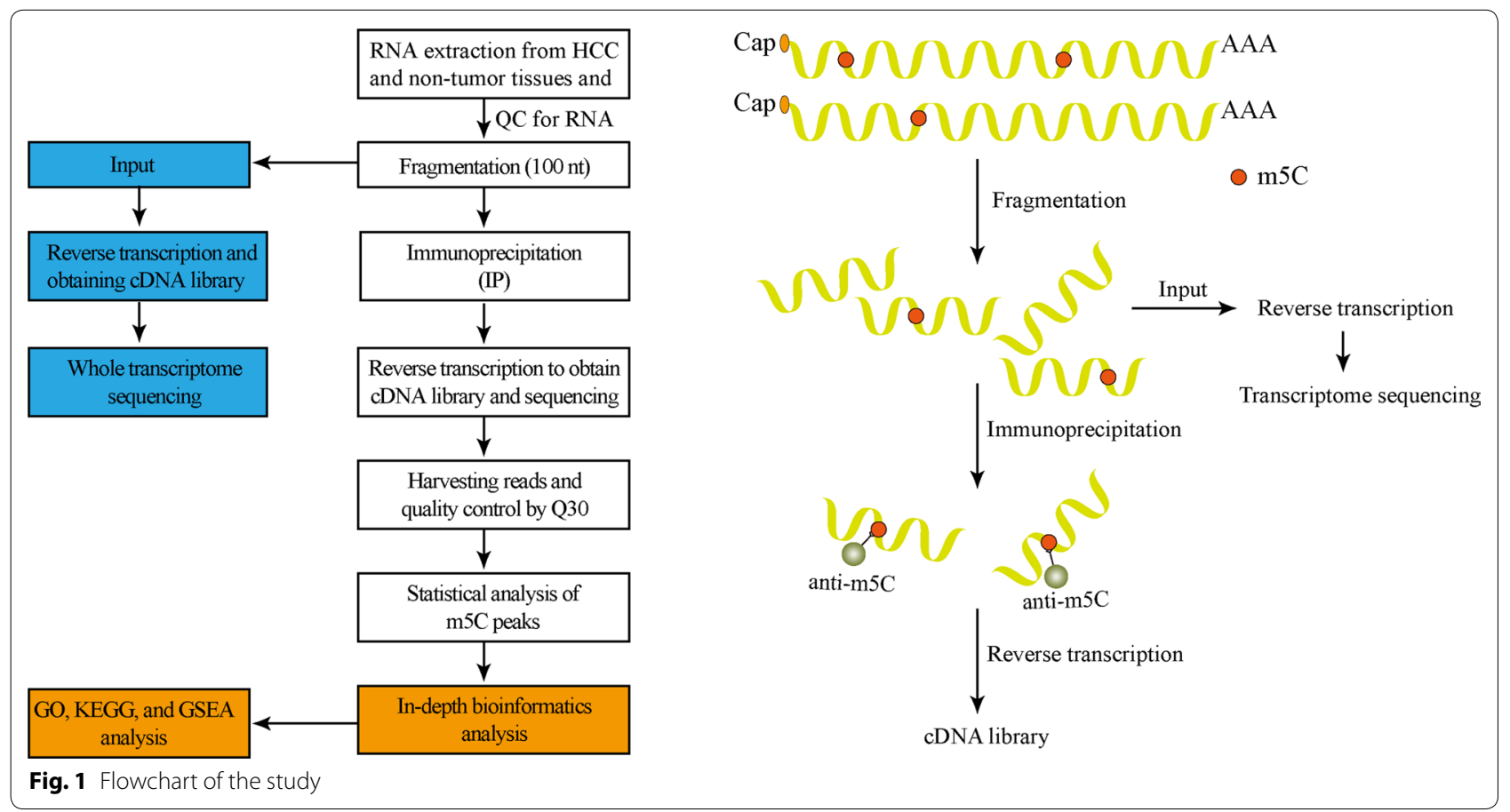




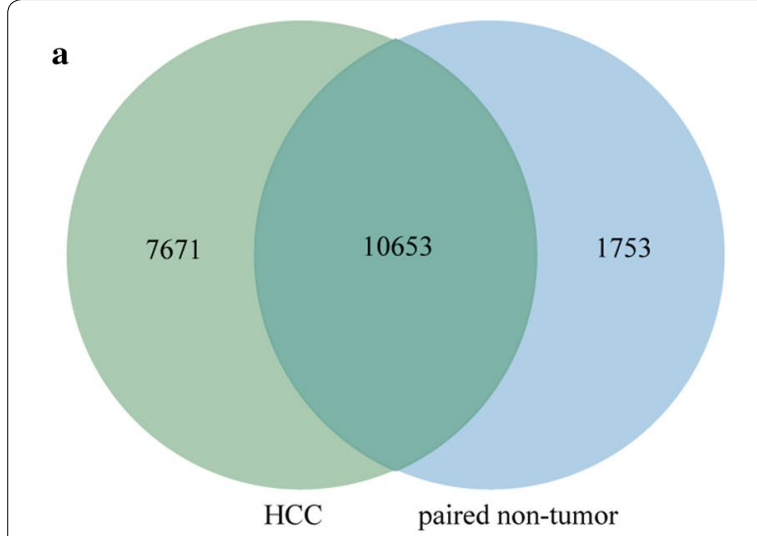

b
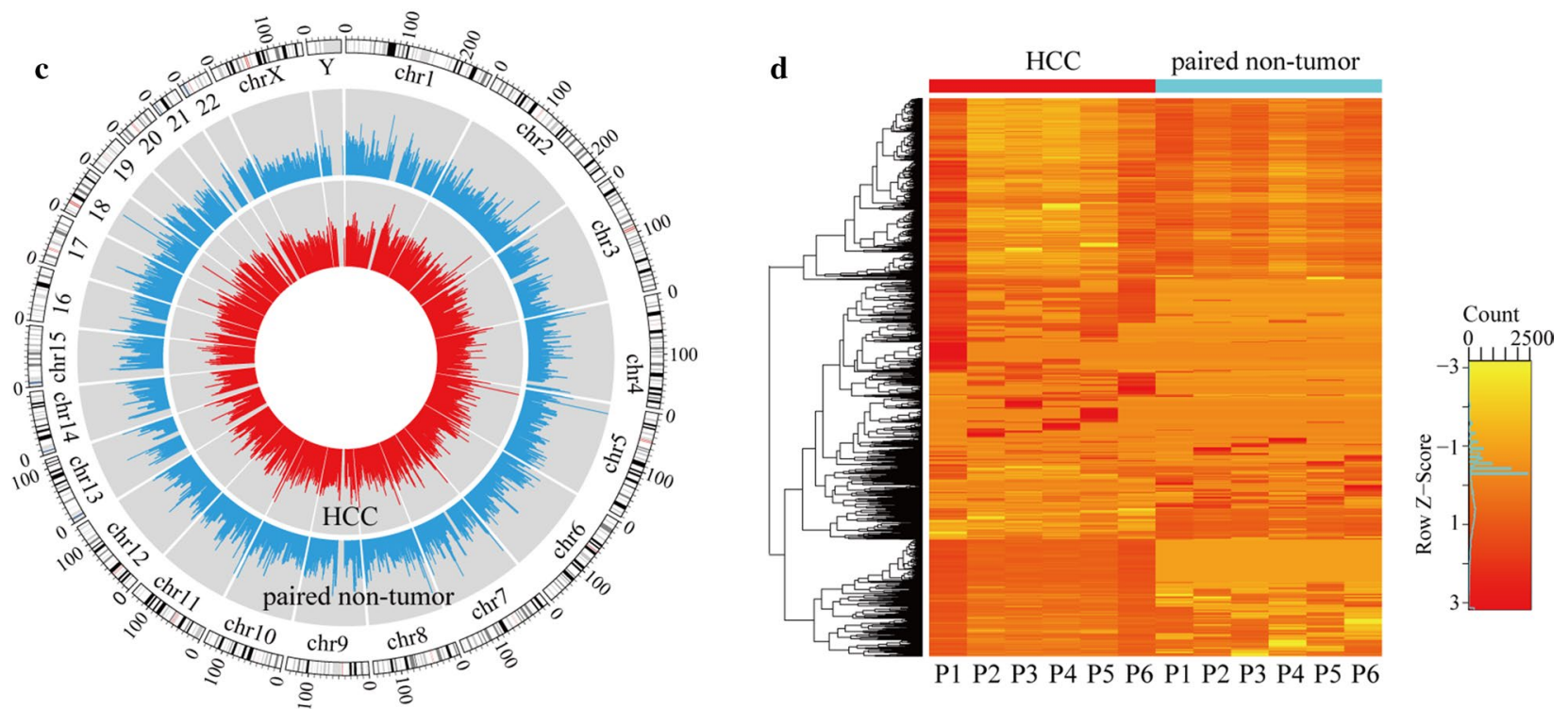

Fig. 2 Overview of mRNA 5-methylcytosine ( $\mathrm{m} 5 \mathrm{C}$ ) in hepatocellular carcinoma (HCC) and adjacent tissues. a Venn diagram of m5C peaks in HCC and adjacent tissues. $\mathbf{b}$ Venn diagram of $\mathrm{m} 5 \mathrm{C}$ genes in HCC and adjacent tissues. c Visualization of m5C at the chromosome level in HCC and adjacent tissues. $\mathbf{d}$ Cluster analysis of $\mathrm{m} 5 \mathrm{C}$ in HCC and adjacent tissues. The color represents the size of the logfold enrichment (FE) value: the closer the color is to red, the larger the logFE value

Table 3 Top ten up-methylated peaks

\begin{tabular}{lrlll}
\hline Chromosome & TxStart & TxEnd & Gene name & Fold change \\
\hline 17 & $44,802,641$ & $44,803,000$ & GJC1 & 166.3 \\
20 & $20,368,103$ & $20,368,560$ & INSM1 & 107.8 \\
8 & $87,871,361$ & $87,871,880$ & DCAF4L2 & 105.5 \\
1 & $27,395,481$ & $27,395,814$ & GPR3 & 53.6 \\
8 & $2,001,041$ & $2,001,420$ & KBTBD11 & 49.958333 \\
6 & $130,438,081$ & $130,438,480$ & TMEM200A & 46.512195 \\
11 & $109,427,881$ & $109,428,300$ & C11Orf87 & 41.321429 \\
1 & $14,924,221$ & $14,924,540$ & KAZN & 40.7 \\
$X$ & $37,728,401$ & $37,728,740$ & XK & 39.196721 \\
9 & $16,416,641$ & $16,417,340$ & BNC2 & 38.307692 \\
\hline
\end{tabular}

Table 4 Top ten down-methylated peaks

\begin{tabular}{lrrll}
\hline Chromosome & TxStart & \multicolumn{1}{l}{ TxEnd } & Gene name & Fold change \\
\hline 11 & $75,083,541$ & $75,084,020$ & OR2AT4 & 139.3 \\
11 & $48,325,401$ & $48,325,840$ & OR4C3 & 134.4 \\
10 & $17,137,441$ & $17,137,840$ & TRDMT1 & 123.9 \\
11 & $4,490,301$ & $4,490,760$ & OR52K1 & 113.9 \\
11 & $102,713,021$ & $102,713,457$ & MMP8 & 109.1 \\
8 & $53,225,801$ & $53,226,240$ & OPRK1 & 108.9 \\
14 & $62,109,501$ & $62,109,960$ & SYT16 & 101.4 \\
$X$ & $50,367,561$ & $50,368,020$ & DGKK & 93.3 \\
11 & $5,069,601$ & $5,070,240$ & OR52E1 & 92.6 \\
$Y$ & $5,740,441$ & $5,740,880$ & PCDH11Y & 92.5 \\
\hline
\end{tabular}




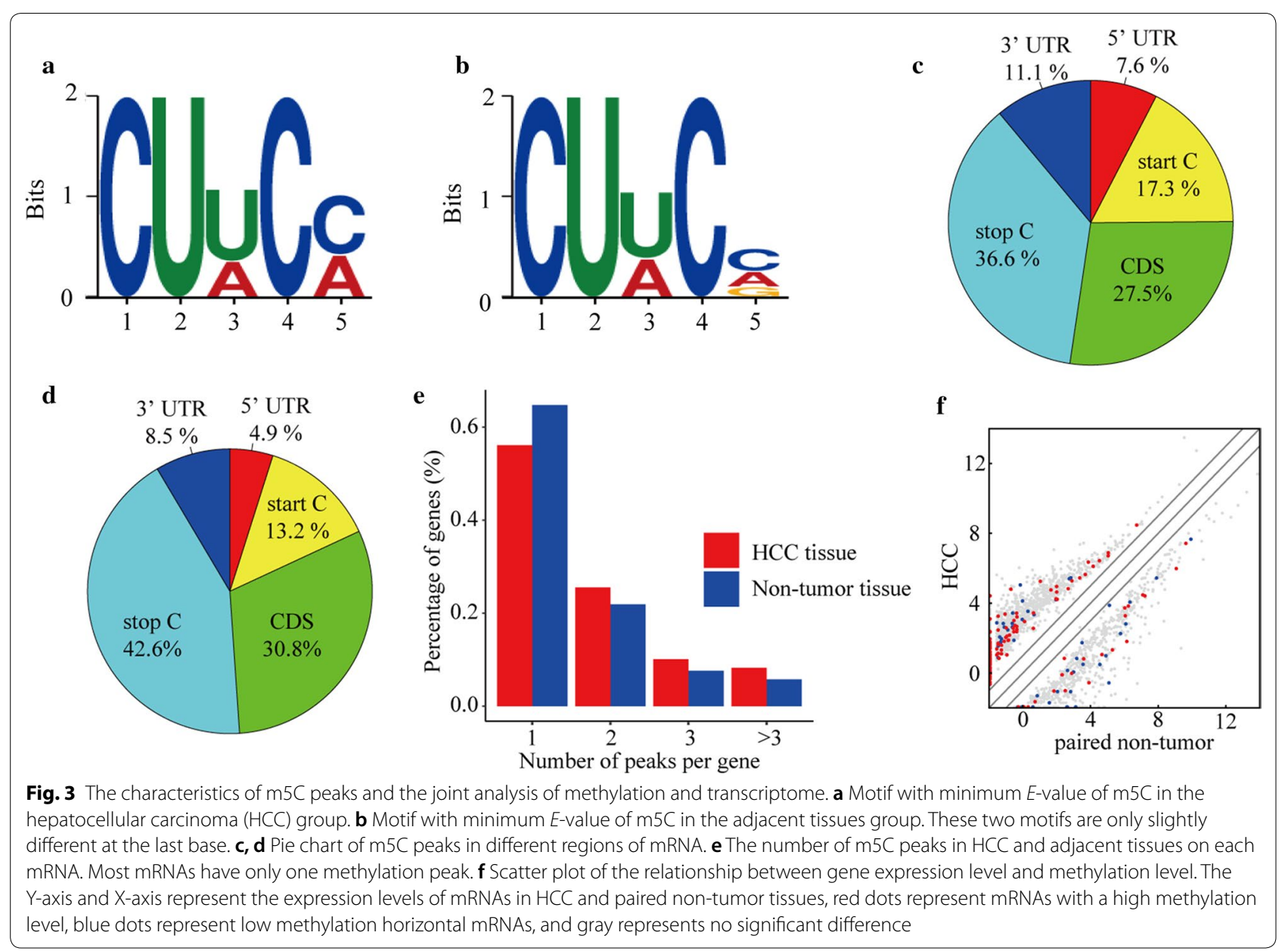

with an $E$-value of $4.6 \mathrm{e}-059$ (Fig. 3a, b). The motif with the lowest $E$-value in the adjacent tissue was CUWCV, with an $E$-value of $4.4 \mathrm{e}-067(\mathrm{~V}=\mathrm{C} / \mathrm{A} / \mathrm{G})$ (Fig. 3a, b). These two motifs were only slightly different at the last base.

\section{Analysis of sources of mRNA methylation in hepatocellular carcinoma and adjacent tissues}

The results of the analysis of the source of methylation peaks showed that $\mathrm{m} 5 \mathrm{C}$ was distributed in all regions of the mRNA (Fig. 3c, d), which is consistent with previous research results $[15,43,44]$, and the distribution in HCC was similar to that in the adjacent tissues (Fig. 3c, d). Specifically, m5C is mostly distributed near the stop codon and least distributed at $5^{\prime} \mathrm{UTR}$ in both groups, which could be related to the length of each region on the mRNA. Compared with adjacent tissues, m5C in HCC was more distributed at both the $3^{\prime} \mathrm{UTR}$ (HCC: 11.1\%, adjacent tissues: $8.5 \%$ ) and $5^{\prime} \mathrm{UTR}$ (HCC: $7.6 \%$, adjacent tissues: $4.9 \%$ ) and less distributed near the stop codon (HCC: $36.6 \%$, adjacent tissues: $42.6 \%$ ).

\section{Statistical analysis of the number of peaks on each mRNA} When we counted the number of $\mathrm{m} 5 \mathrm{C}$ peaks on each mRNA in the two groups, we found that most of the methylated mRNAs (56.1\%) in the HCC tissues had only one $\mathrm{m} 5 \mathrm{C}$ peak, while this index in adjacent tissues was significantly higher $(64.7 \%, \mathrm{p}<0.0001$; Fig. 3e). In addition, the number of $\mathrm{mRNAs}$ with two or more $\mathrm{m} 5 \mathrm{C}$ peaks on one mRNA was higher in HCC tissue than in adjacent tissues $(\mathrm{p}<0.0001)$.

\section{Effect of methylation on transcriptional expression}

Consistent with the above results, the joint analysis of the methylation and transcriptome data showed that there were more up-regulated methylated mRNAs in the HCC group (Fig. 3f). Among the mRNAs that were upmethylated in HCC, 125 mRNAs were up-regulated, and 38 mRNAs were down-regulated. Among the mRNAs that were up-methylated in adjacent tissues, a total of 47 mRNAs were up-regulated, and 48 mRNAs were downregulated. mRNAs with higher degrees of methylation 
tended to have higher expression levels in the HCC group, while this trend was not evident in the adjacent tissues. Moreover, we found that some mRNAs that are rarely expressed in adjacent tissues were highly expressed and hypermethylated in HCC tissues.

\section{Bioinformatics analysis}

The GO analysis of BP found that the genes with upmethylated $\mathrm{m} 5 \mathrm{C}$ sites in $\mathrm{HCC}$ tissues were significantly enriched in system development, multicellular organismal development, and anatomical structure development (Fig. 4a), while the genes with down-methylated m5C were significantly enriched in the detection of chemical stimuli involved in the sensory perception of smell (Fig. 4d). The GO analysis of MF found that the genes with up-methylated $\mathrm{m} 5 \mathrm{C}$ in $\mathrm{HCC}$ tissues were mainly related to sequence-specific DNA binding and nucleic acid binding transcription factor activity (Fig. 4b), while

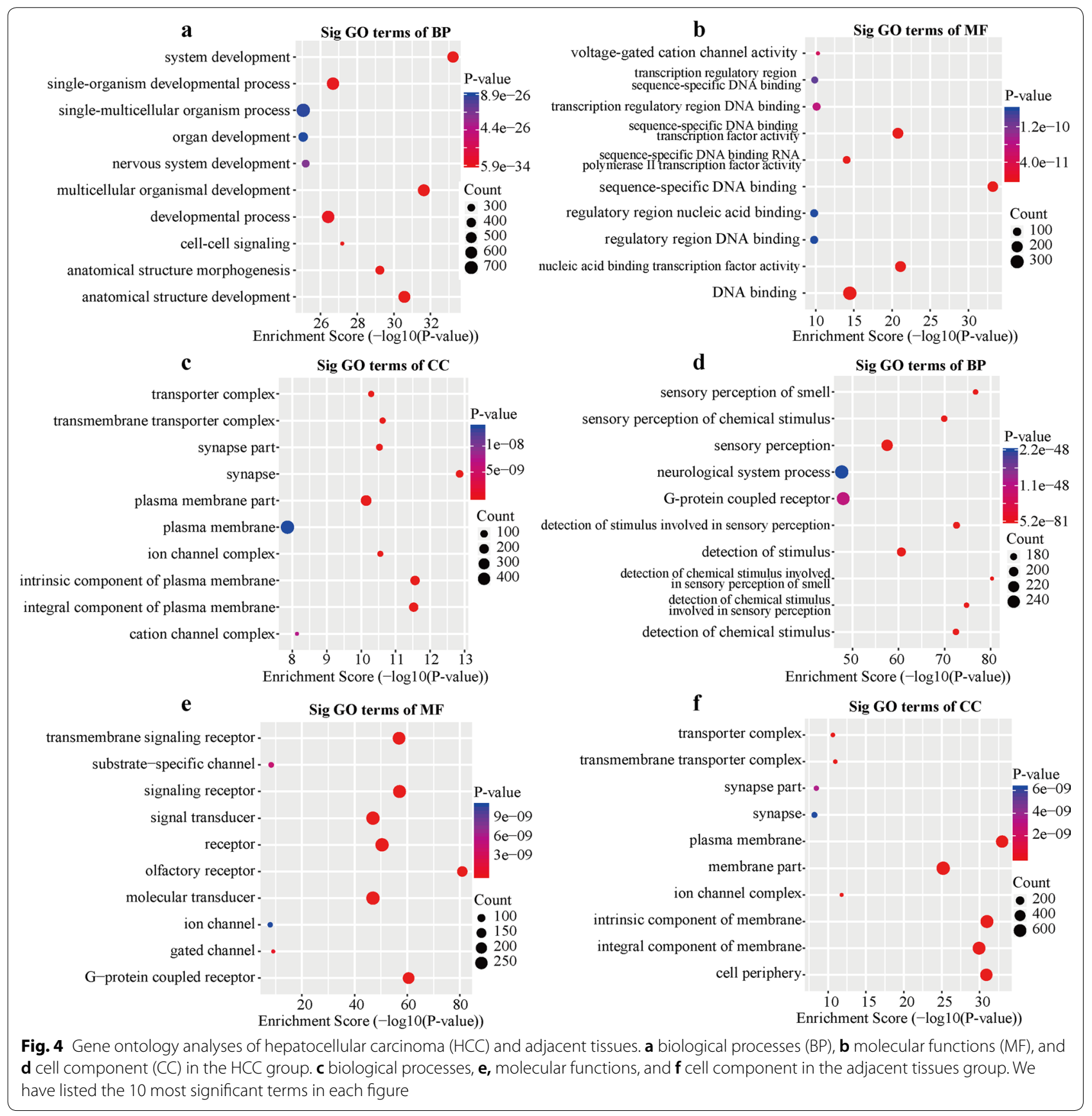


the genes with down-methylated $\mathrm{m} 5 \mathrm{C}$ were primarily related to olfactory receptor activity and $\mathrm{G}$ - protein coupled receptor activity (Fig. 4e). The GO analysis of CC found that the genes with up-methylated $\mathrm{m} 5 \mathrm{C}$ in $\mathrm{HCC}$ tissues were primarily enriched in the synapse, intrinsic, and integral components of plasma membrane (Fig. 4c), which was the same as the genes with up-methylated $\mathrm{m} 5 \mathrm{C}$ in adjacent cancer tissues (Fig. 4f). The KEGG analysis results showed that the mRNAs with up-methylation in HCC tissues were primarily involved in the neuroactive ligand - receptor interaction, calcium signaling pathway, and cAMP signaling pathway (Fig. 5a). The mRNAs with down-methylated $\mathrm{m} 5 \mathrm{C}$ were significantly enriched in olfactory transduction, neuroactive ligand-receptor interaction, and nicotine addiction (Fig. 5b).

\section{Gene set enrichment analysis}

We identified 144 gene sets that were up-regulated and five that were down-regulated in HCC tissues compared with the adjacent tissues. In addition, we identified a particularly down-regulated gene set, KEGG N-glycan biosynthesis (Fig. 5c). When we analyzed other GSEA pathways, focusing on TGF-beta signaling, hedgehog signaling pathway, axon guidance, regulation of actin cytoskeleton, and arrhythmogenic right ventricular cardiomyopathy arc (all p values $<0.05$ ) we found that these pathways are related to the pathogenesis and invasiveness of HCC (Fig. 5d-h) [45-47].

\section{Discussion}

As a post-transcriptional modification, RNA methylation has gradually been shown to be involved in many cellular functions and cancers. Studies have shown that multiple types of RNA methylation ( $\mathrm{m} 5 \mathrm{C}$ and $\mathrm{m} 2 \mathrm{G}$ ) can stabilize RNA fragments in sperm and thus contribute to the identity of sperm RNA as an epigenetic information carrier [48-50]. Research by Li et al. [21, 51] proved that m6A RNA were effective in 33 different types of cancer, including HCC. For example, they found that increased methylation of m6A mRNA is a carcinogenic mechanism of hepatoblastoma (HB). In addition, METTL3 significantly up-regulates $\mathrm{HB}$ and

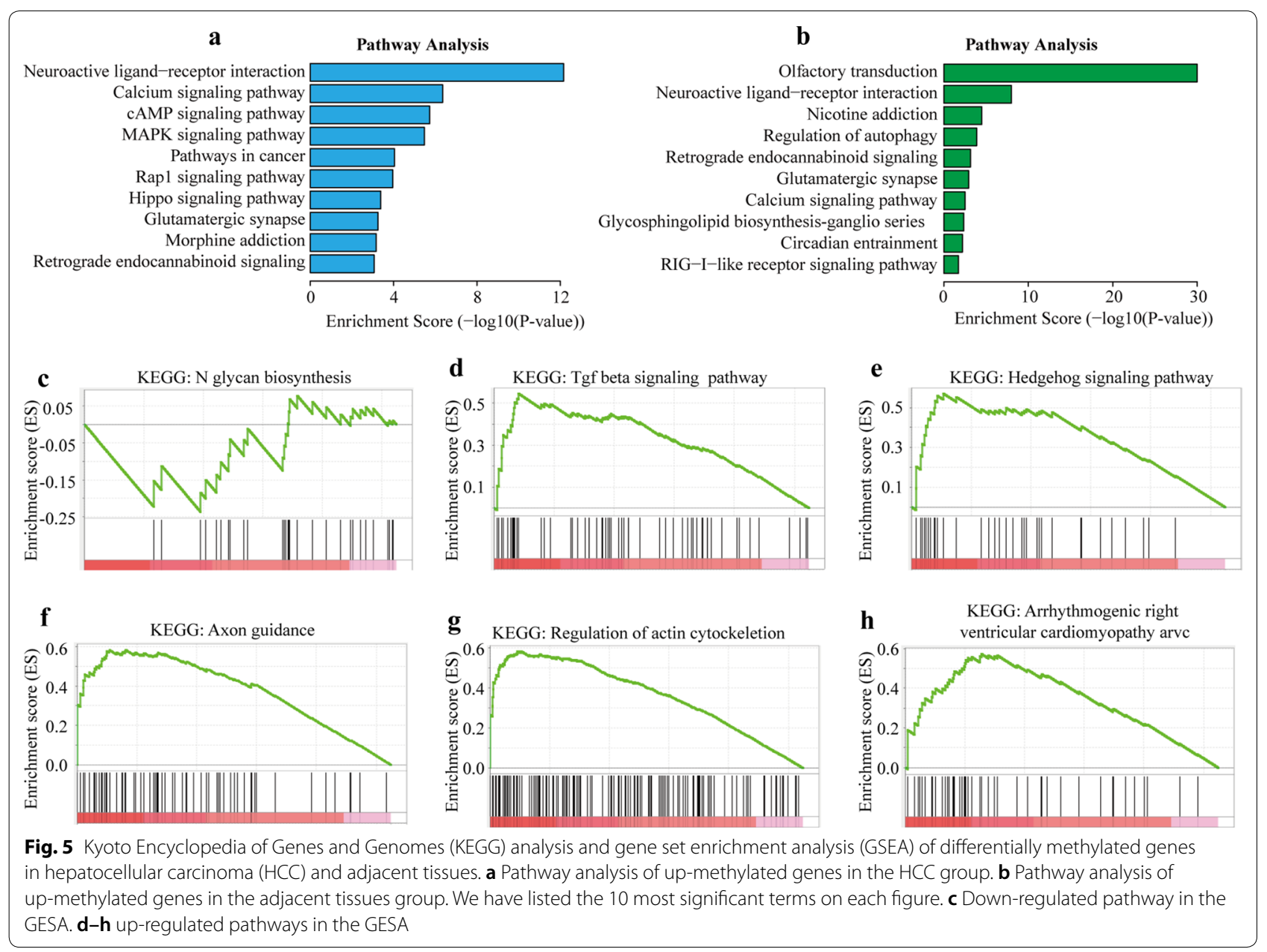


promotes the development of $\mathrm{HB}$, and CTNNB1 has been identified as a regulatory factor for METTL3 to guide m6A to modify $\mathrm{HB}$. As a novel methylation, m5C has been confirmed to play a critical role in regulating RNA nucleation [25], intergenerational transmission of acquired phenotypes [52], and stabilizing mRNAs to promote the proliferation of bladder cancer [31]. To date, the distribution and function of $\mathrm{m} 5 \mathrm{C}$ in hepatocellular carcinoma have not been studied.

We sequenced m5C peaks of mRNA in $\mathrm{HCC}$ and adjacent tissues using MeRIP-seq and analyzed the differences between the two groups. We identified tens of thousands of $\mathrm{m} 5 \mathrm{C}$ peaks in mRNAs and observed significant differences between the two groups. The degree of methylation of mRNA in HCC was significantly higher than in adjacent tissues. In addition, the number of mRNAs mapped using methylation peaks in HCC was markedly higher than in adjacent tissues, which indicates that the role of $\mathrm{m} 5 \mathrm{C}$ in $\mathrm{HCC}$ tissues is more extensive than in adjacent tissues. This finding was also supported by the cluster analysis, in which we found that the two groups can be clearly distinguished by FE of $\mathrm{m} 5 \mathrm{C}$. The $\mathrm{FE}$ of $\mathrm{m} 5 \mathrm{C}$ in $\mathrm{HCC}$ was significantly higher than that in adjacent tissues, especially for some specific mRNAs. As the function of $\mathrm{m} 5 \mathrm{C}$ is not completely clear, we can only make some suggestions: $\mathrm{m} 5 \mathrm{C}$ could play a role in promoting the pathogenesis of HCC through its similar mechanism in bladder cancer, i.e., by stabilizing these mRNAs. The motif analysis also showed that the most credible motif in the two groups was very similar, indicating that the differences in $\mathrm{m} 5 \mathrm{C}$ in the two groups could be due to differences in the number of methylases rather than the category of methylases. This hypothesis could guiding further experiments.

Numerous studies have shown that the distribution of methylation sites in different regions of the mRNA is essential for the stability of mRNA and the regulation of translation. Dominissini et al's study found that m1A is significantly enriched near the start of translation in mammalian and yeast cells and that $\mathrm{m} 1 \mathrm{~A}$ is associated with higher protein expression [53, 54]. Recent studies showed that in eukaryotes, $\mathrm{m} 5 \mathrm{C}$ regulates translation in a negative way $[55,56]$, which could also work through the $\mathrm{m} 5 \mathrm{C}$ sites near the start codon. Our results show that the peaks of $\mathrm{m} 5 \mathrm{C}$ located in the start codon in $\mathrm{HCC}$ are significantly higher than those in the adjacent tissues. Our findings indicate that the expression of some proteins will be reduced, resulting in the deletion of some essential proteins. In addition, we found that there are fewer m5C peaks at the $3^{\prime}$ UTR in HCC, which could also cause differences in cell functions. For example, $\mathrm{m} 5 \mathrm{C}$ at the $3^{\prime} \mathrm{UTR}$ may affect the binding of miRNA or RBPs to mRNA and thus regulate the translation process
[43]. This mechanism has not been proven in HCC, so more sophisticated experiments are needed for further validation.

Research by Huang et al. [57] found that abnormal $\mathrm{N}$-glycosylation of proteins is involved in the development of malignant tumors, including HCC. Interestingly, GSEA of differentially methylated genes in our study showed a significant decrease in N-glycan biosynthesis in HCC tissues. N-glycans are major constituents of glycoproteins in eukaryotes and play an important role in many protein functions, such as protein folding and stability [58]. Abnormal glycosylation caused by the upregulation of fucosyltransferase is closely related to the malignant behavior of the proliferation of HCC [59]. This gene set was significantly down-regulated in HCC $(\mathrm{FDR}=0.208)$, which could suggest that $\mathrm{m} 5 \mathrm{C}$ promotes glycosylation disorders in HCC and causes increased malignant behaviors of HCC tissues. The bioinformatics analysis of GO terms and KEGG pathways showed that $\mathrm{m} 5 \mathrm{C}$ was involved in various aspects of cell function. Although we have a preliminary understanding of the functions of $\mathrm{m} 5 \mathrm{C}$, such as regulating RNA nuclei [25], affecting cell differentiation [60], regulating stem cell function, and stress [61], most of its mechanisms of action, especially in cancer, are still unknown. Therefore, there is a need for more research to establish a detailed understanding of the role of $\mathrm{m} 5 \mathrm{C}$. Our research provides a new perspective for later researchers to study the role of $\mathrm{m} 5 \mathrm{C}$ in $\mathrm{HCC}$ to discover more information on the new therapeutic targets of HCC.

\section{Conclusions}

Our research reveals differences in $\mathrm{m} 5 \mathrm{C}$ in mRNA of hepatocellular carcinoma and adjacent tissues for the first time and shows the distribution and possible function of $\mathrm{m} 5 \mathrm{C}$ through statistical analysis and in-depth bioinformatics analysis. We showed that $\mathrm{m} 5 \mathrm{C}$ has a wide range of functions. However, its role in cells, especially in cancer, remains largely unknown. Therefore, more research is needed to determine its roles.

\footnotetext{
Abbreviations

m5C: 5-Methylcytosine; miRNA: micro RNA; HCC: Hepatocellular carcinoma; ncRNAs: Non-coding RNAs; m6A: N6-Methyladenosine; m1 A: N1-Methyladenosine; GO: Gene ontology; KEGG: Kyoto Encyclopedia of Genes and Genomes; GSEA: Gene set enrichment analysis; BP: Biological processes; MF: Molecular functions; CC: Cellular components; IP: Immunoprecipitation.

\section{Acknowledgements}

We thank the patients who participated in this study and Cloud-Seq Biotech Ltd. Co. (Shanghai, China) for the MeRIP-Seq service.

\section{Authors' contributions}

Zhang QY, HYT and GWZ designed the study; YX searched the articles and made figures; HYT and Zhang QY wrote this manuscript; Zheng QY collected samples. All authors read and approved the final manuscript.
} 


\section{Funding}

This study was supported by funds from the National Natural Science Foundation of China (No 81671958 and 81902832), Science and Technology Innovation Talents in Henan Universities (No 19HASTIT003), Henan Medical Science and Technology Research Project of 2018 (No SBGJ2018002), the Science and Technology Research Project of Henan Province (No 192102310117).

\section{Availability of data and materials}

The datasets used and/or analyzed during the current study are available from the corresponding author on reasonable request.

\section{Ethical approval consent to participate}

The study has been approved by the Ethics Committee of the First Affiliated Hospital of Zhengzhou University (2019-KY-21), and the patient's written informed consent was obtained before the study began.

\section{Consent for publication}

Not applicable.

\section{Competing interests}

The authors declare that there is no conflict of interests.

\section{Author details}

1 Department of Hepatobiliary and Pancreatic Surgery, The First Affiliated Hospital of Zhengzhou University, No.1 Jianshe Road, Zhengzhou 450052, Henan, China. ${ }^{2}$ Key Laboratory of Hepatobiliary and Pancreatic Surgery and Digestive Organ Transplantation of Henan Province, The First Affiliated Hospital of Zhengzhou University, Zhengzhou 450052, China. ${ }^{3}$ Open and Key Laboratory of Hepatobiliary \& Pancreatic Surgery and Digestive Organ Transplantation at Henan Universities, Zhengzhou 450052, China. ${ }^{4}$ Henan Key Laboratory of Digestive Organ Transplantation, Zhengzhou 450052, China.

\section{Received: 8 April 2020 Accepted: 15 June 2020}

Published online: 22 June 2020

\section{References}

1. Ferlay J, Shin HR, Bray F, Forman D, Mathers C, Parkin DM. Estimates of worldwide burden of cancer in 2008: GLOBOCAN 2008. Int J Cancer. 2010;127:2893-917

2. Cai K, Li T, Guo L, Guo H, Zhu W, Yan L, Li F. Long non-coding RNA LINC00467 regulates hepatocellular carcinoma progression by modulating miR-9-5p/PPARA expression. Open Biol. 2019:9:190074.

3. Forner A, Reig M, Bruix J. Hepatocellular carcinoma. Lancet. 2018:391:1301-14.

4. Portolani N, Coniglio A, Ghidoni S, Giovanelli M, Benetti A, Tiberio GA, Giulini SM. Early and late recurrence after liver resection for hepatocellular carcinoma: prognostic and therapeutic implications. Ann Surg. 2006:243:229-35

5. El-Serag HB, Marrero JA, Rudolph L, Reddy KR. Diagnosis and treatment of hepatocellular carcinoma. Gastroenterology. 2008;134:1752-63.

6. He Y, Dang Q, Li J, Zhang Q, Yu X, Xue M, Guo W. Prediction of hepatocellular carcinoma prognosis based on expression of an immune-related gene set. Aging. 2020;12:965-77

7. Yao J, Zhang X, Li J, Zhao D, Gao B, Zhou H, Gao S, Zhang L. Silencing TRIP13 inhibits cell growth and metastasis of hepatocellular carcinoma by activating of TGF-beta1/smad3. Cancer Cell Int. 2018;18:208.

8. Seo SI, Kim HS, Kim WJ, Shin WG, Kim DJ, Kim KH, Jang MK, Lee JH, Kim JS, Kim HY, et al. Diagnostic value of PIVKA-II and alpha-fetoprotein in hepatitis B virus-associated hepatocellular carcinoma. World J Gastroenterol. 2015:21:3928-35.

9. Kumada T, Toyoda H, Kiriyama S, Tanikawa M, Hisanaga Y, Kanamori A, Tada T, Tanaka J, Yoshizawa H. Predictive value of tumor markers for hepatocarcinogenesis in patients with hepatitis C virus. J Gastroenterol. 2011:46:536-44.

10. Chen S, Chen H, Gao S, Qiu S, Zhou H, Yu M, Tu J. Differential expression of plasma microRNA-125b in hepatitis B virus-related liver diseases and diagnostic potential for hepatitis B virus-induced hepatocellular carcinoma. Hepatol Res. 2017:47:312-20.
11. Wang X, Song X, Zhuo W, Fu Y, Shi H, Liang Y, Tong M, Chang G, Luo Y. The regulatory mechanism of Hsp90alpha secretion and its function in tumor malignancy. Proc Natl Acad Sci U S A. 2009;106:21288-93.

12. Garber K. Driving T-cell immunotherapy to solid tumors. Nat Biotechnol. 2018;36:215-9.

13. Delaunay $S$, Frye M. RNA modifications regulating cell fate in cancer. Nat Cell Biol. 2019:21:552-9.

14. Edelheit S, Schwartz S, Mumbach MR, Wurtzel O, Sorek R. Transcriptomewide mapping of 5-methylcytidine RNA modifications in bacteria, archaea, and yeast reveals m5C within archaeal mRNAs. PLoS Genet. 2013;9:e1003602

15. Dominissini D, Moshitch-Moshkovitz S, Schwartz S, Salmon-Divon M, Ungar L, Osenberg S, Cesarkas K, Jacob-Hirsch J, Amariglio N, Kupiec M, et al. Topology of the human and mouse m6A RNA methylomes revealed by m6A-seq. Nature. 2012;485:201-6.

16. Wang X, Lu Z, Gomez A, Hon GC, Yue Y, Han D, Fu Y, Parisien M, Dai Q, Jia $\mathrm{G}$, et al. N6-methyladenosine-dependent regulation of messenger RNA stability. Nature. 2014:505:117-20.

17. Zhao X, Yang Y, Sun BF, Shi Y, Yang X, Xiao W, Hao YJ, Ping XL, Chen YS, Wang WJ, et al. FTO-dependent demethylation of N6-methyladenosine regulates $m R N A$ splicing and is required for adipogenesis. Cell Res. 2014;24:1403-19.

18. Wang X, Zhao BS, Roundtree IA, Lu Z, Han D, Ma H, Weng X, Chen K, Shi $\mathrm{H}, \mathrm{He}$ C. N(6)-methyladenosine modulates messenger RNA translation efficiency. Cell. 2015;161:1388-99.

19. Xiao W, Adhikari S, Dahal U, Chen YS, Hao YJ, Sun BF, Sun HY, Li A, Ping XL, Lai WY, et al. Nuclear m(6)A reader YTHDC1 regulates mRNA splicing. Mol Cell. 2016;61:507-19.

20. Amort T, Rieder D, Wille A, Khokhlova-Cubberley D, Riml C, Trixl L, Jia XY, Micura R, Lusser A. Distinct 5-methylcytosine profiles in poly(A) RNA from mouse embryonic stem cells and brain. Genome Biol. 2017:18:1.

21. Li Y, Xiao J, Bai J, Tian Y, Qu Y, Chen X, Wang Q, Li X, Zhang Y, Xu J. Molecular characterization and clinical relevance of $\mathrm{m}(6)$ A regulators across 33 cancer types. Mol Cancer. 2019;18:137.

22. Helm M. Post-transcriptional nucleotide modification and alternative folding of RNA. Nucleic Acids Res. 2006:34:721-33.

23. Agris PF. Bringing order to translation: the contributions of transfer RNA anticodon-domain modifications. EMBO Rep. 2008;9:629-35.

24. Schaefer M, Pollex T, Hanna K, Lyko F. RNA cytosine methylation analysis by bisulfite sequencing. Nucleic Acids Res. 2009;37:e12.

25. Yang X, Yang Y, Sun BF, Chen YS, Xu JW, Lai WY, Li A, Wang X, Bhattarai DP, Xiao W, et al. 5-methylcytosine promotes mRNA export-NSUN2 as the methyltransferase and ALYREF as an m(5)C reader. Cell Res. 2017;27:606-25.

26. Gigova A, Duggimpudi S, PollexT, Schaefer M, Kos M. A cluster of methylations in the domain IV of $25 \mathrm{~S}$ rRNA is required for ribosome stability. RNA. 2014:20:1632-44.

27. Schaefer M, Pollex T, Hanna K, Tuorto F, Meusburger M, Helm M, Lyko F. RNA methylation by Dnmt2 protects transfer RNAs against stress-induced cleavage. Genes Dev. 2010;24:1590-5.

28. Sharma S, Yang J, Watzinger P, Kotter P, Entian KD. Yeast Nop2 and Rcm1 methylate C2870 and C2278 of the 25S rRNA, respectively. Nucleic Acids Res. 2013:41:9062-76.

29. Tuorto F, Liebers R, Musch T, Schaefer M, Hofmann S, Kellner S, Frye M, Helm M, Stoecklin G, Lyko F. RNA cytosine methylation by Dnmt2 and NSun2 promotes tRNA stability and protein synthesis. Nat Struct Mol Biol. 2012;19:900-5.

30. David R, Burgess A, Parker B, Li J, Pulsford K, Sibbritt T, Preiss T, Searle IR. Transcriptome-Wide Mapping of RNA 5-Methylcytosine in Arabidopsis mRNAs and Noncoding RNAs. Plant Cell. 2017:29:445-60.

31. Chen X, Li A, Sun BF, Yang Y, Han YN, Yuan X, Chen RX, Wei WS, Liu Y, Gao CC, et al. 5-methylcytosine promotes pathogenesis of bladder cancer through stabilizing mRNAs. Nat Cell Biol. 2019;21:978-90.

32. Luo Z, Zhang Z, Tai L, Zhang L, Sun Z, Zhou L. Comprehensive analysis of differences of N(6)-methyladenosine RNA methylomes between high-fatfed and normal mouse livers. Epigenomics. 2019:11:1267-82.

33. Dobin A, Davis CA, Schlesinger F, Drenkow J, Zaleski C, Jha S, Batut P, Chaisson M, Gingeras TR. STAR: ultrafast universal RNA-seq aligner. Bioinformatics. 2013:29:15-21.

34. Cheng J, Metge F, Dieterich C. Specific identification and quantification of circular RNAs from sequencing data. Bioinformatics. 2016:32:1094-6. 
35. Kim D, Langmead B, Salzberg SL. HISAT: a fast spliced aligner with low memory requirements. Nat Methods. 2015;12:357-60.

36. Zhang Y, Liu T, Meyer CA, Eeckhoute J, Johnson DS, Bernstein BE, Nusbaum C, Myers RM, Brown M, Li W, Liu XS. Model-based analysis of ChIP-Seq (MACS). Genome Biol. 2008;9:R137.

37. Shen L, Shao NY, Liu X, Maze I, Feng J, Nestler EJ. diffReps: detecting differential chromatin modification sites from ChIP-seq data with biological replicates. PLOS ONE. 2013;8:e65598.

38. Bailey TL. DREME: motif discovery in transcription factor ChIP-seq data. Bioinformatics. 2011;27:1653-9.

39. Luo GZ, MacQueen A, Zheng G, Duan H, Dore LC, Lu Z, Liu J, Chen K, Jia $\mathrm{G}$, Bergelson J, He C. Unique features of the m6A methylome in Arabidopsis thaliana. Nat Commun. 2014:5:5630.

40. Anders S, Pyl PT, Huber W. HTSeq-a Python framework to work with highthroughput sequencing data. Bioinformatics. 2015;31:166-9.

41. Robinson MD, McCarthy DJ, Smyth GK. edgeR: a Bioconductor package for differential expression analysis of digital gene expression data. Bioinformatics. 2010;26:139-40.

42. da Huang W, Sherman BT, Lempicki RA. Systematic and integrative analysis of large gene lists using DAVID bioinformatics resources. Nat Protoc. 2009;4:44-57.

43. Squires JE, Patel HR, Nousch M, Sibbritt T, Humphreys DT, Parker BJ, Suter CM, Preiss T. Widespread occurrence of 5-methylcytosine in human coding and non-coding RNA. Nucleic Acids Res. 2012;40:5023-33.

44. Meyer KD, Saletore Y, Zumbo P, Elemento O, Mason CE, Jaffrey SR. Comprehensive analysis of mRNA methylation reveals enrichment in $3^{\prime}$ UTRs and near stop codons. Cell. 2012;149:1635-46.

45. Wang YH, Sui XM, Sui YN, Zhu QW, Yan K, Wang LS, Wang F, Zhou JH. BRD4 induces cell migration and invasion in HCC cells through MMP-2 and MMP-9 activation mediated by the Sonic hedgehog signaling pathway. Oncol Lett. 2015;10:2227-32.

46. Qu Z, Feng J, Pan H, Jiang Y, Duan Y, Fa Z. Exosomes derived from HCC cells with different invasion characteristics mediated EMT through TGFbeta/Smad signaling pathway. Onco Targets Ther. 2019;12:6897-905.

47. Huang D, Cao L, Xiao L, Song JX, Zhang YJ, Zheng P, Zheng SG. Hypoxia induces actin cytoskeleton remodeling by regulating the binding of CAPZA1 to F-actin via PIP2 to drive EMT in hepatocellular carcinoma. Cancer Lett. 2019:448:117-27.

48. Chen Q, Yan W, Duan E. Epigenetic inheritance of acquired traits through sperm RNAs and sperm RNA modifications. Nat Rev Genet. 2016;17:733-43.

49. Zhang X, Cozen AE, Liu Y, Chen Q, Lowe TM. Small RNA modifications: integral to function and disease. Trends Mol Med. 2016;22:1025-34.

50. Liu L, Wang J, Sun G, Wu Q, Ma J, Zhang X, Huang N, Bian Z, Gu S, Xu M, et al. m(6)A mRNA methylation regulates CTNNB1 to promote the proliferation of hepatoblastoma. Mol Cancer. 2019;18:188.
51. Chen Y, Peng C, Chen J, Chen D, Yang B, He B, Hu W, Zhang Y, Liu H, Dai L, et al. WTAP facilitates progression of hepatocellular carcinoma via m6AHuR-dependent epigenetic silencing of ETS1. Mol Cancer. 2019;18:127.

52. Zhang Y, Zhang X, Shi J, Tuorto F, Li X, Liu Y, Liebers R, Zhang L, Qu Y, Qian , et al. Dnmt2 mediates intergenerational transmission of paternally acquired metabolic disorders through sperm small non-coding RNAs. Nat Cell Biol. 2018;20:535-40.

53. Li X, Xiong X, Wang K, Wang L, Shu X, Ma S, Yi C. Transcriptome-wide mapping reveals reversible and dynamic N(1)-methyladenosine methylome. Nat Chem Biol. 2016;12:311-6.

54. Dominissini D, Nachtergaele S, Moshitch-Moshkovitz S, Peer E, Kol N, Ben-Haim MS, Dai Q, Di Segni A, Salmon-Divon M, Clark WC, et al. The dynamic N(1)-methyladenosine methylome in eukaryotic messenger RNA. Nature. 2016;530:441-6.

55. Hoernes TP, Clementi N, Faserl K, Glasner H, Breuker K, Lindner H, Huttenhofer A, Erlacher MD. Nucleotide modifications within bacterial messenger RNAs regulate their translation and are able to rewire the genetic code. Nucleic Acids Res. 2016;44:852-62.

56. Delatte B, Wang F, Ngoc LV, Collignon E, Bonvin E, Deplus R, Calonne E, Hassabi B, Putmans P, Awe S, et al. RNA biochemistry Transcriptomewide distribution and function of RNA hydroxymethylcytosine. Science. 2016;351:282-5.

57. Huang Y, Zhou S, Zhu J, Lubman DM, MechrefY. LC-MS/MS isomeric profiling of permethylated $\mathrm{N}$-glycans derived from serum haptoglobin of hepatocellular carcinoma (HCC) and cirrhotic patients. Electrophoresis. 2017;38:2160-7.

58. Cherepanova NA, Gilmore R. Mammalian cells lacking either the cotranslational or posttranslocational oligosaccharyltransferase complex display substrate-dependent defects in asparagine linked glycosylation. Sci Rep. 2016;6:20946

59. Cheng L, Gao S, Song X, Dong W, Zhou H, Zhao L, Jia L. Comprehensive $\mathrm{N}$-glycan profiles of hepatocellular carcinoma reveal association of fucosylation with tumor progression and regulation of FUT8 by microRNAs. Oncotarget. 2016;7:61199-214.

60. Flores JV, Cordero-Espinoza L, Oeztuerk-Winder F, Andersson-Rolf A, Selm T, Blanco S, Tailor J, Dietmann S, Frye M. Cytosine-5 RNA methylation regulates neural stem cell differentiation and motility. Stem Cell Reports. 2017:8:112-24.

61. Blanco S, Bandiera R, Popis M, Hussain S, Lombard P, Aleksic J, Sajini A, Tanna H, Cortes-Garrido R, Gkatza N, et al. Stem cell function and stress response are controlled by protein synthesis. Nature. 2016;534:335-40.

\section{Publisher's Note}

Springer Nature remains neutral with regard to jurisdictional claims in published maps and institutional affiliations.
Ready to submit your research? Choose BMC and benefit from:

- fast, convenient online submission

- thorough peer review by experienced researchers in your field

- rapid publication on acceptance

- support for research data, including large and complex data types

- gold Open Access which fosters wider collaboration and increased citations

- maximum visibility for your research: over $100 \mathrm{M}$ website views per year

At BMC, research is always in progress.

Learn more biomedcentral.com/submissions 